\title{
Die Sanktionierung von Aufsichtspflichtverletzungen in der öffentlichen Verwaltung
}

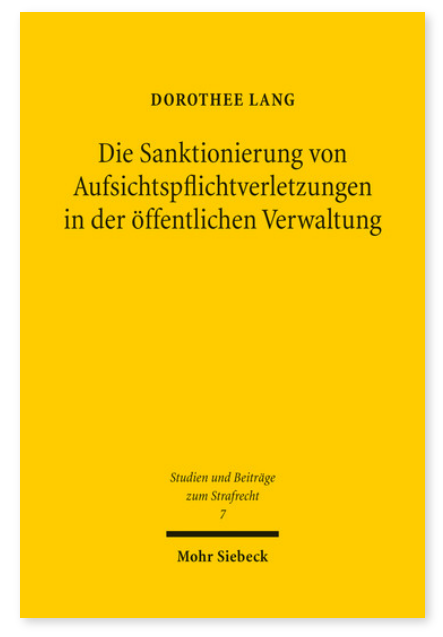

2016. XVIII, 305 Seiten. StudStR 7

ISBN 978-3-16-154674-7

DOI 10.1628/978-3-16-154674-7

eBook PDF 89,00€

ISBN 978-3-16-154659-4

fadengeheftete Broschur $89,00 €$
Unter dem Begriff der sogenannten Geschäftsherrenhaftung diskutiert Dorothee Lang, ob und wann vorgesetzte Leitungspersonen für das Fehlverhalten unterstellter Mitarbeiter einzustehen haben. Angeknüpft wird dabei an das Unterlassen von Aufsichtsmaßnahmen. Während die bisherige Diskussion ausschließlich den Bereich der Privatwirtschaft im Blick hatte, nimmt die Autorin nun Führungspersonen der öffentlichen Verwaltung unter die Lupe. Dabei berücksichtigt sie, dass das Vertrauen der Allgemeinheit in die Integrität und die Funktionsfähigkeit der öffentlichen Verwaltung eigenständigem strafrechtlichem Schutz unterliegt. Um zu klären, ob die bestehenden Sanktionsmöglichkeiten einem umfassenden Rechtsgüterschutz genügen, werden insbesondere § 357 Abs. 1 Var. 3 StGB, eine Unterlassensstrafbarkeit i.V.m. § 13 Abs. 1 StGB, eine Ahndung nach § $130 \mathrm{OWiG}$ sowie disziplinarische Maßnahmen gegenübergestellt.

Dorothee Lang Geboren 1988; Studium der Rechtswissenschaften an der Ludwig-Maximilians-Universität München; Wissenschaftliche Angestellte am Lehrstuhl für Deutsches und Europäisches Straf- und Strafprozessrecht, Wirtschaftsstrafrecht und Computerstrafrecht in Konstanz und Tübingen; seit 2015 Rechtsreferendarin im OLG-Bezirk Nürnberg.
Jetzt bestellen:

https://mohrsiebeck.com/buch/die-sanktionierung-von-aufsichtspflichtverletzungen-in-der-oeffentlichen-verwaltung9783161546747?no_cache=1

order@mohrsiebeck.com

Telefon: $+49(0) 7071-923-17$

Telefax: $+49(0) 7071-51104$ 